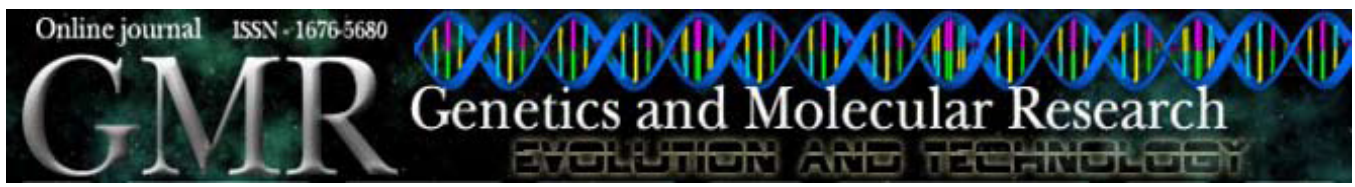

\title{
Effects of immature cashew nut-shell liquid (Anacardium occidentale) against oxidative damage in Saccharomyces cerevisiae and inhibition of acetylcholinesterase activity
}

S.G. De Lima ${ }^{1}$, C.M. Feitosa ${ }^{1}$, A.M.G.L. Citó ${ }^{1}$, J.M. Moita Neto ${ }^{1}$, J.A.D. Lopes ${ }^{1}$, A.S. Leite ${ }^{2}$, M.C. Brito ${ }^{2}$, S.M.M. Dantas and A.A.C. Melo Cavalcante ${ }^{2}$

${ }^{1}$ Departamento de Química, Universidade Federal do Piauí, Centro de Ciências da Natureza, Campus Universitário Ministro Petrônio Portella, Teresina, PI, Brasil

${ }^{2}$ Departamento de Biologia, Universidade Federal do Piauí, Centro de Ciências da Natureza, Campus Universitário Ministro Petrônio Portella, Teresina, PI, Brasil

Corresponding author: A.A.C. Melo Cavalcante

Email: ana_ameliamelo@ibest.com.br

Genet. Mol. Res. 7 (3): 806-818 (2008)

Received June 16, 2008

Accepted July 2, 2008

Published September 9, 2008

\begin{abstract}
The cashew tree (Anacardium occidentale) represents one of the major cheapest sources of non-isoprenoid phenolic lipids, which have a variety of biological properties: they can act as molluscicides, insecticides, fungicides, have anti-termite properties, have medicinal applications, and demonstrate antioxidant activity in vitro. Immature cashew nut-shell liquid (iCNSL) is a unique natural source of unsaturated long-chain phenols. Their use has stimulated much research in order to prepare drug analogues for application in several fields. The objective of the present study was to determine whether iCNSL has antioxidant properties when used in strains of the yeast Saccharomyces cerevisiae and to measure the inhibitory activity of acetylcholinesterase.
\end{abstract}


The constituents were identified using thin-layer chromatography, gas chromatography-mass spectrometry, Fourier transform infrared spectroscopy, and ${ }^{1} \mathrm{H}$ and ${ }^{13} \mathrm{C}$ nuclear magnetic resonance. The iCNSL contains anacardic acid, cardanol, cardol, and 2-methyl cardol. Immature cashew nut oil contains triacylglycerols, fatty acids, alkyl-substituted phenols, and cholesterol. The main constituents of the free fatty acids are palmitic $\left(\mathrm{C}_{16: 0}\right)$ and oleic acid $\left(\mathrm{C}_{18: 1}\right)$. iCNSL has excellent protective activities in strains of $S$. cerevisiae against oxidative damage induced by hydrogen peroxide and inhibits acetylcholinesterase activity. iCNSL may have an important role in protecting DNA against damage induced by reactive oxygen species, as well as hydrogen peroxide, generated by intra- and extracellular mechanisms.

Key words: Cashew nut oil; Anacardium occidentale; Antioxidant activity; Acetylcholinesterase

\section{INTRODUCTION}

The cashew tree, Anacardium occidentale, originates from Brazil and is well established in many tropical regions. Cashew apple juice has been reported to have anti-tumor and antimicrobial properties (Kubo et al., 1993a,b; Kozubek et al., 2001). Cashew apple juice and cajuina, the clarified juice, also have excellent antioxidant potential, as evidenced by their ability to scavenge free radicals, their antimutagenic properties (Melo-Cavalcante et al., 2003, 2005) and their antioxidant activity in vitro (Melo-Cavalcante et al., 2003; Trevisan et al., 2006; Kamath and Rajini, 2007).

The fruit of the tree consists of an outer shell (epicarp), a tight-fitting inner shell (endocarp), and a strongly vesicant cashew nut-shell liquid (CNSL, Figure 1). The CNSL is contained between the inner and outer shell (pericarp) in a honeycomb matrix. Besides the valuable cashew nut, the cashew tree is the source of many useful by-products, including the peduncle of the nut or pseudo-fruit (cashew apple) that is used to make juices and wines (da Silva et al., 2000). CNSL is a unique natural source of meta-alkyl phenols with a variable degree of unsaturation attached to the benzene ring (Figure 2). Based on the mode of extraction from the cashew nut-shell, CNSL is classified into two types: solvent-extracted immature CNSL (iCNSL) and technical CNSL. A typical solvent-extracted material contains anacardic acid (60-65\%), cardol (15-20\%), cardanol (10\%), and traces of 2-methyl cardol. Depending on the conditions of the roasting process, the composition of the technical CNSL can change and have higher cardanol content (83-84\%), less cardol (8-11\%) and maintain polymeric material at 10\% and 2-methyl cardol content at 2\% (dos Santos and de Magalhães, 1999; Ikeda et al., 2002; Kumar et al., 2002). Its constituents have been widely used as "synthon" for the preparation of many compounds with potential biological activities (dos Santos and de Magalhães, 1999; Kumar et al., 2002; Resck et al., 2005; Logrado et al., 2005). Lasiodiplosina, a 12-member orcelinic-type macrolideo, which occurs naturally, has plant growth regulating properties and antileucemic activity, and has been synthesized from anacardic acid. Other applications are the synthesis of polymers (De Lima et al., 1997; dos Santos and de Magalhães, 1999; Kumar et al., 2002) and agricultural products (Kumar et al., 2002). 


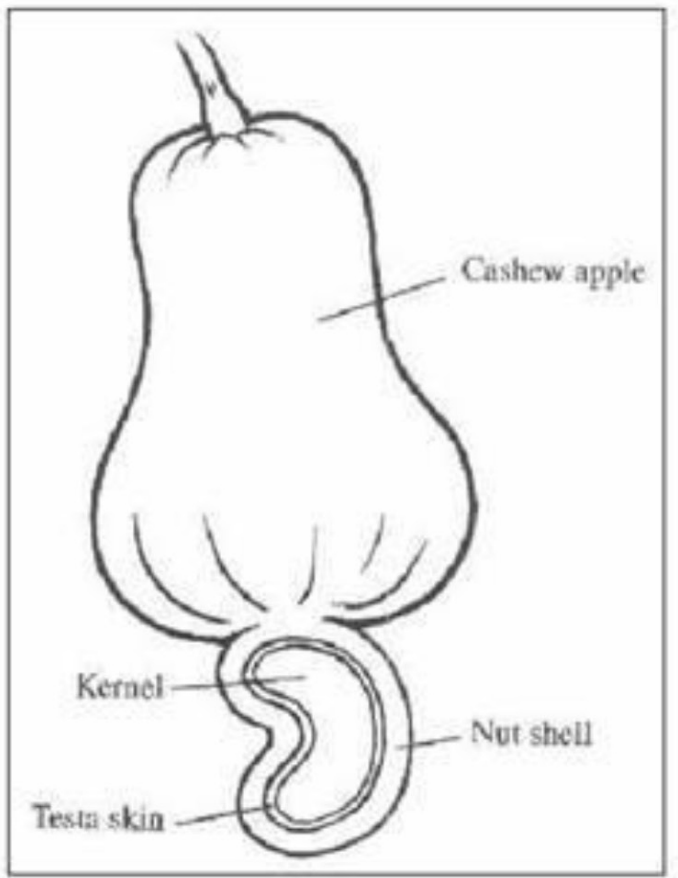

Figure 1. Cross section of a cashew fruit. Adapted according to Azam-Ali and Judge (2001).

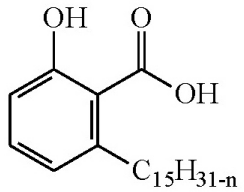

(1)

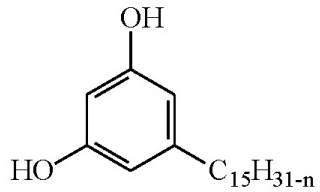

(2)<smiles>CCCCCCc1cccc(O)c1</smiles>

(3)

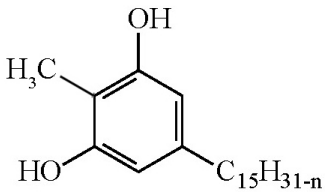

(4)

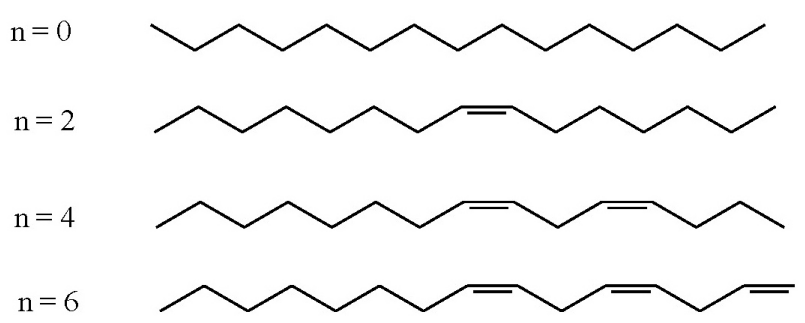

Figure 2. Naturally occurring non-isoprenoid phenolic lipids from Anacardium occidentale. $(\underline{\mathbf{1}})$ = anacardic acid; $(\underline{\mathbf{2}})=$ cardols; $(\underline{\mathbf{3}})=$ cardanols; $(\underline{\mathbf{4}})=2$-methyl cardols . 
The oxygen consumption inherent in cell growth leads to the generation of a series of oxygen free radicals. Free radical formation is associated with the normal natural metabolism of aerobic cells and can be defined as molecules or molecular fragments containing one or more unpaired electrons in atomic or molecular orbitals (Halliwell and Gutteridge, 1999). Reactive oxygen species (ROS) such as $\mathrm{O}_{2} \bullet-, \mathrm{H}_{2} \mathrm{O}_{2}$, and $\bullet \mathrm{OH}$ are produced as normal by-products of aerobic cellular metabolism or through exposure to environmental agents, such as radiation, stimulated host phagocytes, or redox cycling agents. ROS can cause damage to biological macromolecules, such as proteins and lipids. Cellular injury from ROS has been implicated in the development and progression of several diseases (Smith et al., 2000; Skerget et al., 2005).

Antioxidant compounds can scavenge free radicals and increase shelf life by retarding the process of lipid peroxidation, which is one of the major reasons for deterioration of food products during processing and storage (Halliwell and Gutteridge, 1999). Thus, there is a need to identify alternative, natural and safe sources of food antioxidants. The search for natural antioxidants, especially of plant origin, has notably increased in recent years (Skerget et al., 2005). The eukaryotic yeast Saccharomyces cerevisiae has been extensively studied both genetically and biochemically, and is widely used in biological screening and testing. As with all aerobes, S. cerevisiae possesses a variety of antioxidant defenses, including a cytoplasmic $\mathrm{Cu}^{2+}$ and $\mathrm{Zn}^{2+} \mathrm{SOD}$ (CuZnSOD, SOD1), coded for by the SOD1 gene, a mitochondrial manganese SOD (MnSOD, SOD2), coded for by the $S O D 2$ gene, a cytoplasmic catalase coded for by the $C C T 1$ gene and a peroxisomal catalase coded for by the CCA1 gene (Steinman, 1980; Marres et al., 1985).

Acetylcholinesterase (AChE) plays an important role in neurotransmission at cholinergic synapses by rapidly hydrolyzing the excitatory neurotransmitter acetylcholine into choline and acetic acid (Massoulie et al., 1993; Stasiuk et al., 2008). It is present in cholinergic synapses of the central nervous system and in neuromuscular synapses where it rapidly hydrolyses acetylcholine. AChE is responsible for preventing re-excitation, after stimulated cells have recovered from a first action potential (Stasiuk et al., 2008).

The aim of the present study was to investigate the antioxidant properties of CNSL in vivo, of iCNSL in mutant strains of S. cerevisiae that are deficient in antioxidant defenses and its ability to inhibit AChE. In addition, the chemical composition of compounds and concentration of phenolic lipids were evaluated.

\section{MATERIAL AND METHODS}

\section{Chemicals}

All solvents were bi-distilled and stored in dark flasks. Analytical grade anhydrous sodium sulfate was heated to $300^{\circ} \mathrm{C}$ before using $\mathrm{H}_{2} \mathrm{O}_{2}$. Dimethylsulfoxides (DMSO) were purchased from Sigma (St. Louis, USA). Yeast extract, Bacto-peptone and Bacto-agar were obtained from Difco Laboratories (Detroit, MI, USA). Acetylthiocholine iodide and DTNB (5-5'-dithiobis (2-nitro-benzoic acid) were purchased from Sigma-Aldrich (Poznan, Poland). All other products used in the experiments were of analytical grade. Chromatography was carried out on Vetec silica gel $60(0.063-0.200 \mathrm{~mm})$ and Merck silica gel $60(0.2-0.5 \mathrm{~mm})$. The solvents were obtained from Merck (analytical grade). 


\section{Plant material}

The sample of iCNSL was prepared from fresh cashew nut collected from cashew plants (A. occidentale) of the Universidade Federal do Piauí, in the city of Teresina (Northeast Brazil).

\section{Extraction and purification}

Nuts were cleaned and dried, and the shells were removed and cut into small bits. Twenty grams of shell and also of the test skin (Figure 1) were extracted in a Soxhlet apparatus for $6 \mathrm{~h}$. The hexanic fraction of shell $(2.0 \mathrm{~g})$ was chromatographed on a silica gel column with a gradient of hexane, ethyl acetate and acetic acid yielding 57 fractions.

\section{System analysis}

Nuclear magnetic resonance (NMR)

NMR spectra were recorded on a Bruker 500 spectrometer $\left(11.7\right.$ Tesla, $500 \mathrm{MHz}$ for ${ }^{1} \mathrm{H}$ and $125 \mathrm{MHz}$ for ${ }^{13} \mathrm{C}$ ), in $\mathrm{CDCl}_{3}$. Chemical shifts $\delta$ (in ppm) are given from internal tetramethylsilane (TMS).

\section{Fourier transform infrared spectroscopy (FT-IR)} $\left.400 \mathrm{~cm}^{-1}\right)$.

The FT-IR spectra were recorded on a BOMEM - MB 100 spectrometer (4000 to

\section{Gas chromatography-mass spectrometry (GC-MS)}

Analysis of the fractions was performed on Shimadzu GC-17A/MS QP5050A (GC-MS system): DB-5HT capillary column (30 m x $0.251 \mathrm{~mm}, 0.1 \mu \mathrm{m}$ film thickness); carrier gas: helium $1.7 \mathrm{~mL} / \mathrm{min}$; column inlet pressure $107.8 \mathrm{kPa}$; column flow $=1.7 \mathrm{~mL} /$ min; linear velocity $=47.3 \mathrm{~cm} / \mathrm{s}$; total flow $24 \mathrm{~mL} / \mathrm{min}$; carrier flow $24 \mathrm{~mL} / \mathrm{min}$; injector temperature $280^{\circ} \mathrm{C}$; detector temperature $300^{\circ} \mathrm{C}$; column temperature $100(1 \mathrm{~min})-310^{\circ} \mathrm{C}$ at $10^{\circ} \mathrm{C} / \mathrm{min}(15 \mathrm{~min})$. Mass spectrometer operating conditions were $70 \mathrm{eV}$ of ionization energy. Mass spectra were recorded from $40-450 \mathrm{~m} / \mathrm{z}$. The percent of area was obtained electronically from the GC-MS response without the use of an internal standard or correction factors.

\section{Methylation and alkylthiolation reaction}

The iCNSL fraction was subjected to methylation with diazomethane according to De Lima (2005). Methyl esters were prepared by treatment with an excess of previously prepared ethereal diazomethane and maintained at $-20^{\circ} \mathrm{C}$. The reaction, after $3 \mathrm{~h}$, yielded methyl esters quantitatively, and took place at $5^{\circ} \mathrm{C}$. The solvent was then evaporated in a vacuum. A small portion of the crude reaction was analyzed in GC-MS.

The position of the double bonds of unsaturated hydrocarbons was determined by io- 
dine-catalyzed methylthiolation using dimethyl disulfide - DMDS (Wang, 1998; Lizhi, 2003). To a solution of phenolic fraction $(50 \mathrm{mg})$ in DMDS $(0.3 \mathrm{~mL})$ at $25^{\circ} \mathrm{C} 10 \mathrm{mg}$ iodide and $3 \mathrm{~mL}$ ethyl ether were added. The mixture was stirred at $25^{\circ} \mathrm{C}$, for $4 \mathrm{~h}$. After reduction of the excess $\mathrm{I}_{2}$ with a saturated $\mathrm{NaHSO}_{3}$ aqueous solution, $3 \mathrm{~mL}$ hexane was added to the mixture. One microliter of the hexanic phase was injected into the GC-MS.

\section{Antioxidant assays in S. cerevisiae}

S. cerevisiae and isogenic mutants were kindly provided by Dr. E. Gralla (University of California, Los Angeles, USA). SOD1 and SOD2 genes were disrupted as previously described by Gralla and Valentine (1991) and Liu et al. (1992). The strains used and their relevant genotypes are listed in Table 1 . Yeast cells were grown overnight in YPD $(0.5 \%$ yeast extract, $2 \%$ bacto-peptone, and $2 \%$ glucose) medium at $28^{\circ} \mathrm{C}$ in an orbital shaker until they reached the stationary growth phase, according to Rosa et al. (2006). A suspension containing $1 \times 10^{8}$ cells $/ \mathrm{mL}$ was shaken for $3 \mathrm{~h}$ at $30^{\circ} \mathrm{C}$ with several concentrations of $\mathrm{HME}$ in phosphate buffer (0.067 M, pH 7.0). Cells were then harvested by centrifugation and washed twice with phosphate buffer. Cell density was determined using a Neubauer counting chamber and the sensitivity to $\mathrm{H}_{2} \mathrm{O}_{2}(10 \mathrm{mM})$ was estimated by the spot test. In this case, after treatment, a $10-\mu \mathrm{L}$ drop of each decimal dilution $\left(10^{8}-10^{3}\right.$ cells $\left./ \mathrm{mL}\right)$ was spotted onto $S$. cerevisiae plates containing the oxidant agents. The doses of iCNSL and gallic acid were $200 \mu \mathrm{g} / \mathrm{mL}$, a concentration that does not show toxicity. An inoculation loop of cells from a suspension treated with various concentrations of Ebselen (dissolved in DMSO) was streaked from the center to the border of a Petri dish in one continuous stroke, to both sides of the plate. Plates were incubated for 2 days at $30^{\circ} \mathrm{C}$. The antioxidant evaluation was done by the following treatments: $\mathrm{H}_{2} \mathrm{O}_{2}$ $(10 \mathrm{mM})$; gallic acid $(200 \mu \mathrm{g} / \mathrm{mL})$; iCNSL $(200 \mu \mathrm{g} / \mathrm{mL})$; gallic acid $+\mathrm{H}_{2} \mathrm{O}_{2} ; \mathrm{iCNSL}+\mathrm{H}_{2} \mathrm{O}_{2}$. A filter-paper disk was placed in the center of the plate and the oxidizing agent was applied onto the disk for all treatments. Impairment growth was measured as centimeter of growth inhibition from the border of the filter-disk to the beginning of cellular growth. Values can range from $0 \mathrm{~cm}$ (complete growth to the filter-disk) to $4 \mathrm{~cm}$ (absence of growth to the rim of the Petri dish). The oxidizing agent used in the disk assay was $5 \mu \mathrm{L} 10 \mathrm{mM}$ hydrogen peroxide in aqueous solution. All assays were carried out in triplicate.

Table 1. Description of the Saccharomyces cerevisiae strains used in the present study.

\begin{tabular}{|c|c|}
\hline Designation & Genotype \\
\hline EG103 (WT) & MATa leu2-3,112 trp1-289 ura3-52 $\mathrm{AAL}^{+}$ \\
\hline EG118 $(\operatorname{sod} 1 \Delta)$ & sod $1:$ URA3 all other markers as EG103 \\
\hline EG110 $(\operatorname{sod} 2 \Delta)$ & sod2::TRP1 all other markers as EG103 \\
\hline EG133 $(\operatorname{sod} 1 \Delta \operatorname{sod} 2 \Delta)$ & sod $1::$ URA 3 sod $2::$ TRP1 double mutant all other markers as EG103 \\
\hline EG223 (cat $\Delta l)$ & EG103, except cat $1::$ TRP1 \\
\hline $\mathrm{EG}(\operatorname{sod} 1 \Delta$ cat 1$)$ & EG103, except sod $1::$ URA3 and cat $1::$ TRP1 \\
\hline
\end{tabular}

\section{Estimation of acetylcholinesterase activity}

Acetylcholinesterase activity was assayed using the method of Ellman et al. (1961), Fenech (1993) and Rhee et al. (2001), in which acetylthiocholine was used as the substrate 
and the product, thiocholine, after reaction with DTNB forming a yellow anion, 5-thio-2nitrobenzoic acid, as the indicator of enzymatic activity.

\section{Statistical analysis}

Statistical analyses were calculated using one-way ANOVA of the Statistical Package for the Social Science (SPSS 15.0 for windows release 15.0.1.11). The Dunnett test was used to determine whether the means of the treatments differed significantly compared to a positive control at the level of $\mathrm{P}<0.01$.

\section{RESULTS AND DISCUSSION}

\section{iCNSL characterization}

The identification of chemical constituents of iCNSL and of the immature nut oil was carried out using FT-IR, thin-layer chromatography (TLC), GC-MS and/or $\mathrm{H}^{1}$ and ${ }^{13} \mathrm{C}$ NMR and compared with data from scientific studies (Murthy et al., 1968; Silva et al., 2005; De Lima, 2005). The analyses of the iCNSL indicated that it has a similar composition to the technical CNSL (anacardic acids, cardols and cardanols). However, technical CNSL contains mainly cardanol and cardol (Figure 2). A GC-MS analysis indicated the presence of 10 constituents, with the main ones being monounsaturated anacardic acid (69\%), cardol (13.8\%) and cardanols (7.86\%). A lower relative amount of the compounds 1-tridecanyl-3-hydroxy benzene $(0.56 \%)$ and traces of methyl cardol were detected.

A batch of iCNSL was chromatographed on silica gel. The lesser polar fractions of iCNSL (from F-2 to F-23) were analyzed by FT-IR, GC-MS and NMR and compared with literature data (Murthy et al., 1968; Silva et al., 2005), indicating the presence of a mixture of cardanols [(즈), $n$ $=0,1,2$ and 3]. The NMR ${ }^{1} \mathrm{H}$ spectrum of the F-44 fraction showed signals at $7.15 \mathrm{ppm}(\mathrm{m}, 1 \mathrm{H}$, H-5); 6.75 ppm (d, 1H, H-4); 6.65 ppm (s, 1H, H-2); 6.60 ppm (d, 1H, H-6); 5.38 ppm (m, 2H, H-8'

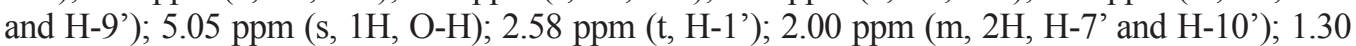
$\mathrm{ppm}\left(\mathrm{sl}, \mathrm{nCH}_{2}\right) ; 0.85 \mathrm{ppm}\left(\mathrm{t}, 3 \mathrm{H}, \mathrm{CH}_{3}\right)$ and the NMR spectrum of ${ }^{13} \mathrm{C}$ showed signals at $155.5 \mathrm{ppm}$ (C-1); 145.0 ppm (C-3); 131.0 and 130.4 ppm $(\mathrm{C}=\mathrm{C}) ; 129.6$ ppm (C-5); 121.0 ppm (C-4); 115.5 ppm (C-6); $112.5 \mathrm{ppm}(\mathrm{C}-2)$. The remaining signals observed between 36.0 and $22.0 \mathrm{ppm}$ in proton noise decoupled (PND) and non-inverted in distortionless enhancement by polarization transfer (DEPT) $135^{\circ}$ were attributed to the methylenic carbons. All signals present in the NMR spectrums of ${ }^{1} \mathrm{H}$ and ${ }^{13} \mathrm{C}$ are common to the two cardanols (saturated and monounsaturated), except for the multiplet, at $5.38 \mathrm{ppm}$, in the NMR spectrum of ${ }^{1} \mathrm{H}$ and the two signals at 130.4 and $131.0 \mathrm{ppm}$, observed in the NMR spectrum of ${ }^{13} \mathrm{C}$ (PND) and not inverted in DEPT 135, which were attributed to the two hydrogen atoms and the oleofinic carbon atoms, respectively, confirming the presence of monounsaturated cardanol: $(\underline{3}), \mathrm{n}=2$.

The mixture of cardanols was confirmed by GC-MS analysis, indicating the presence of the respective molecular ions: $\mathrm{m} / \mathrm{z} 312, \mathrm{~m} / \mathrm{z} 314, \mathrm{~m} / \mathrm{z} 316$, and $\mathrm{m} / \mathrm{z} 318$. The fractions with medium polarity (F-35 to F-40) were also analyzed by TLC, FT-IR and GC-MS, and showed the predominant presence of monounsaturated anacardic acid. The fractions with highest polarity, F-50, F-51 and F-53, were also analyzed by FT-IR and GC-MS, confirming the presence of cardol. The mass spectrum of monounsaturated anacardic acid in the form of methylic ester is shown 
in Figure 3. Both the phenolic hydroxyl and the hydroxyl of the carboxylic OH group were methylated. The characteristic fragments are represented by the peak that refers to the molecular ion $\mathrm{m} / \mathrm{z} 374, \mathrm{~m} / \mathrm{z} 314$ (McLafferty rearrangement), $\mathrm{m} / \mathrm{z} 343$ (loss of $\mathrm{CH}_{3} \mathrm{O}$ ) and by the peak at $\mathrm{m} / \mathrm{z} 180$ (allylic rearrangement, break 1-2).
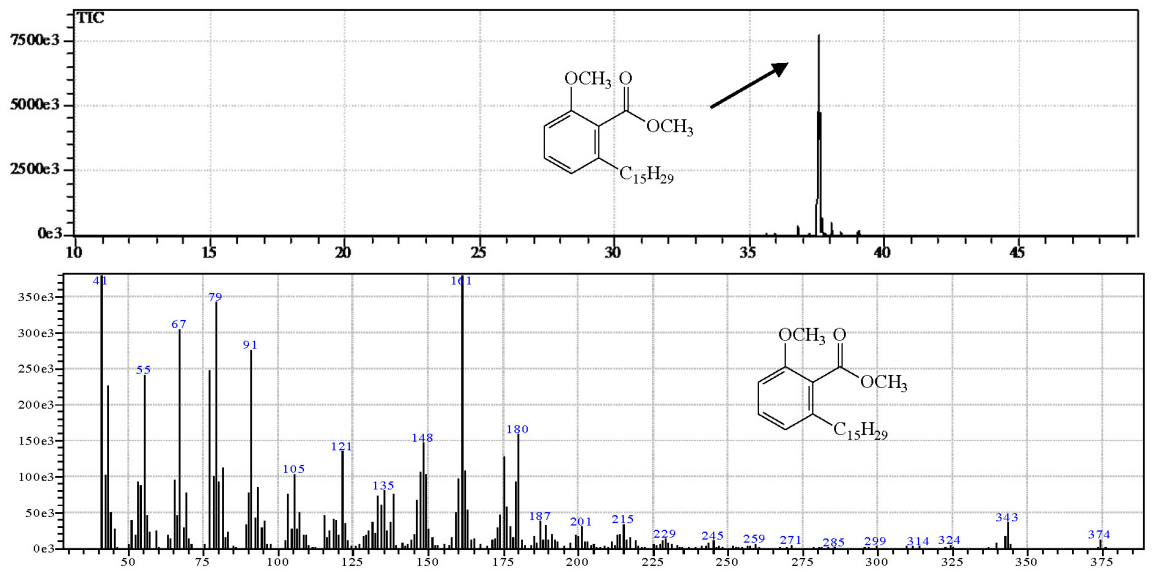

Figure 3. Gas chromatography-mass spectrometry of the unsaturated anacardic acid as methyl ester, compound (1) $-\mathrm{n}=2$.

The determination of the positions of double bonds after the addition of DMDS is described for cardanol and anacardic acid as ester. The mass spectra (electron impact $70 \mathrm{eV}$ ) show molecular ions $\left(\mathrm{M}^{+}\right)$and give key fragments that permit the determination of the original double bond. Cleavage between the sulfur-substituted carbons leads to key fragments which allow the determination of the double bond in the original mono-unsaturated phenolic compound. The spectrometer was set to scan ions $\mathrm{m} / \mathrm{z}$ 396, 381, 154, and 107 for the cardanol fraction (with the double bond at C-8), while for the methylated anacardic acid fraction we detected ions $\mathrm{m} / \mathrm{z} 468$ $\left(\mathrm{M}^{+}\right), 453,323$, and 145 as the characteristic fragments.

\section{Characterization of membrane iCNSL}

The immature nut's oil has a similar composition to the oil of the mature nut: triglycerides, alkyl-substituted phenolic compounds and free fatty acids, the main component of which is oleic acid $\left(\mathrm{C}_{18: 1}\right)$, as described in previous studies on mature nut oil (Toschi et al., 1993). Preliminary essays developed by our laboratory indicated the presence of these phenolic lipids in the tegument too (the skin that separates the shell from the nut). The presence of phenolic lipids in the cashew nut-shell, in the nut and in the cashew apple has already been noted previously. The immature nut oil, when analyzed by TLC, apart from a spot correspondent with triglycerides, was extremely similar to the CNSL, indicating the presence of alkyl-substituted phenolic composites (Kubo et al., 1986; Shobha and Ravindranath, 1991). The presence of cholesterol was also detected in a TLC analysis (Toschi et al., 1993). The infrared spectrum showed the main characteristic as being a band of strong absorption in $1745 \mathrm{~cm}^{-1}$, attributed to carbonyl triglycerides. The GC-MS analysis of the residue methylated with diazomethane confirmed the presence of free fatty acids, with a predominance of peaks correspondent to the derivatives of palmitic $\left(\mathrm{C}_{16: 0}\right)$ and oleic acids, in line with the 
data of the literature (Toschi et al., 1993).

\section{Antioxidant assays in $S$. cerevisiae}

In this article, iCNSL was studied to determine its in vivo antioxidant activity. This protective property, shown by an increase in survival, is the same for all strains, independent of the antioxidant defense disrupted. Table 2 and Figure 4 clearly show that incubation of the strains with iCNSL results in an increase survival after $\mathrm{H}_{2} \mathrm{O}_{2}$ treatment, for strains of $S$. cerevisiae defective in antioxidant defense. Treatment with iCNSL protected $S$. cerevisiae strains against oxidative damage, showing a clear and excellent antioxidant action with the percent of inhibition at about $70 \%$ (Figure 5). No significant difference was observed between iCNSL and gallic acid. The fact that iCNSL had a better performance, may be due to the presence of alkyl polyunsaturated phenols. Due to these properties, further studies could be made to examine the possibility of using iCNSL as a natural antioxidant (Table 2). Gallic acid exhibited antigenotoxic activity when used against $\mathrm{H}_{2} \mathrm{O}_{2}$-stressed cells detected by the Comet assay because it directly influenced DNA activity; it also repaired enzymes and modulated their gene expression, suggesting that this compound is an antimutagen (Abdelwahed et al., 2007).

Table 2. Growth inhibitory $(\mathrm{cm})$ effects of immature cashew nut-shell liquid (iCNSL) in strains of Saccharomyces
cerevisiae.
\begin{tabular}{lcccccc}
\hline Treatment & SOD $\Delta$ & sod $1 \Delta$ & sod $2 \Delta$ & sod $1 /$ sod $2 \Delta$ & cat $1 \Delta$ & sod1/cat $1 \Delta$ \\
\hline $\mathrm{H}_{2} \mathrm{O}_{2}(10 \mathrm{mM})$ & $2.65 \pm 0.2$ & $2.65 \pm 0.2$ & $2.50 \pm 0.1$ & $2.52 \pm 0.1$ & $2.65 \pm 0.1$ & $2.47 \pm 0.1$ \\
$\mathrm{Gallic}$ acid $(200 \mu \mathrm{gg} / \mathrm{mL})$ & $0.00 \pm 0.0$ & $0.00 \pm 0.0$ & $0.00 \pm 0.0$ & $0.00 \pm 0.0$ & $0.00 \pm 0.0$ & $0.00 \pm 0.0$ \\
iCNSL $(200 \mu \mathrm{g} / \mathrm{mL})$ & $0.00 \pm 0.0$ & $0.00 \pm 0.0$ & $0.00 \pm 0.0$ & $0.00 \pm 0.0$ & $0.00 \pm 0.0$ & $0.00 \pm 0.0$ \\
Gallic acid $+\mathrm{H}_{2} \mathrm{O}_{2}$ & $1.27 \pm 0.1^{*}$ & $1.12 \pm 0.2^{*}$ & $1.12 \pm 0.3^{*}$ & $1.42 \pm 0.2^{*}$ & $1.35 \pm 0.1^{*}$ & $1.22 \pm 0.1^{*}$ \\
iCNSL $+\mathrm{H}_{2} \mathrm{O}_{2}$ & $0.90 \pm 0.1^{*}$ & $0.92 \pm 0.1^{*}$ & $0.87 \pm 0.2^{*}$ & $0.87 \pm 0.2^{*}$ & $1.00 \pm 0.1^{*}$ & $0.90 \pm 0.2^{*}$ \\
\hline
\end{tabular}

Data are reported as means $\pm \mathrm{SD}$ for $\mathrm{N}=4$. Data represent the average of at least three independent experiments. Statistical significance, one-way ANOVA followed by the Dunnett multiple comparison test $\left({ }^{*} \mathrm{P}<0.01\right)$.

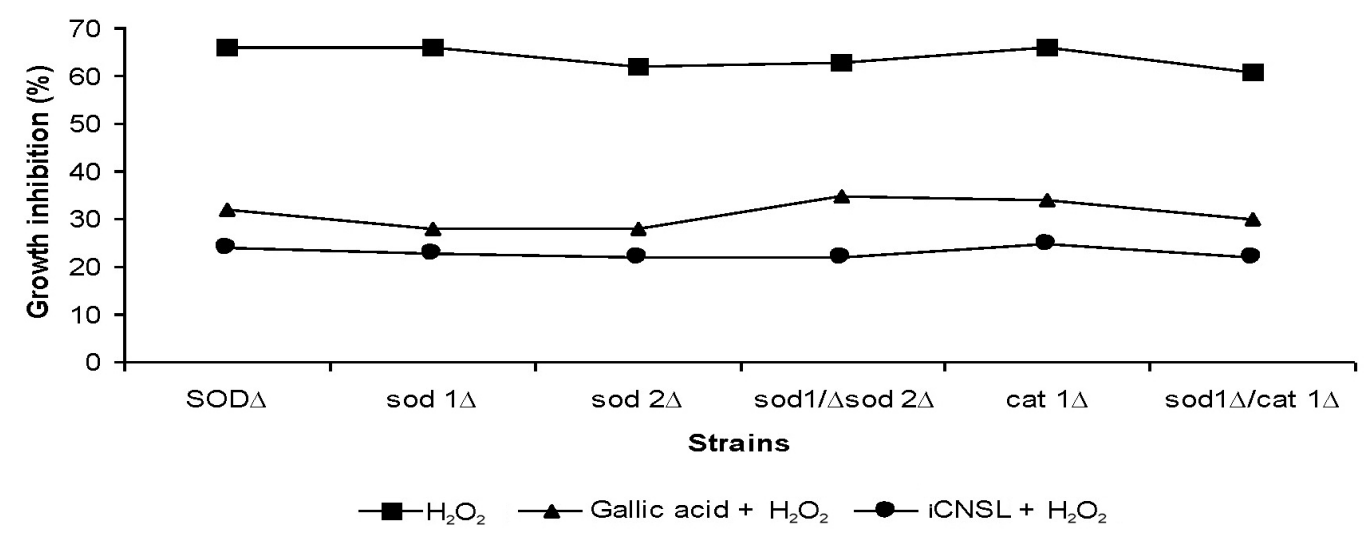

Figure 4. Protective effect of immature cashew nut-shell liquid (iCNSL) in Saccharomyces cerevisiae against oxidative damage induced by $\mathrm{H}_{2} \mathrm{O}_{2}(10 \mathrm{mM})$. 


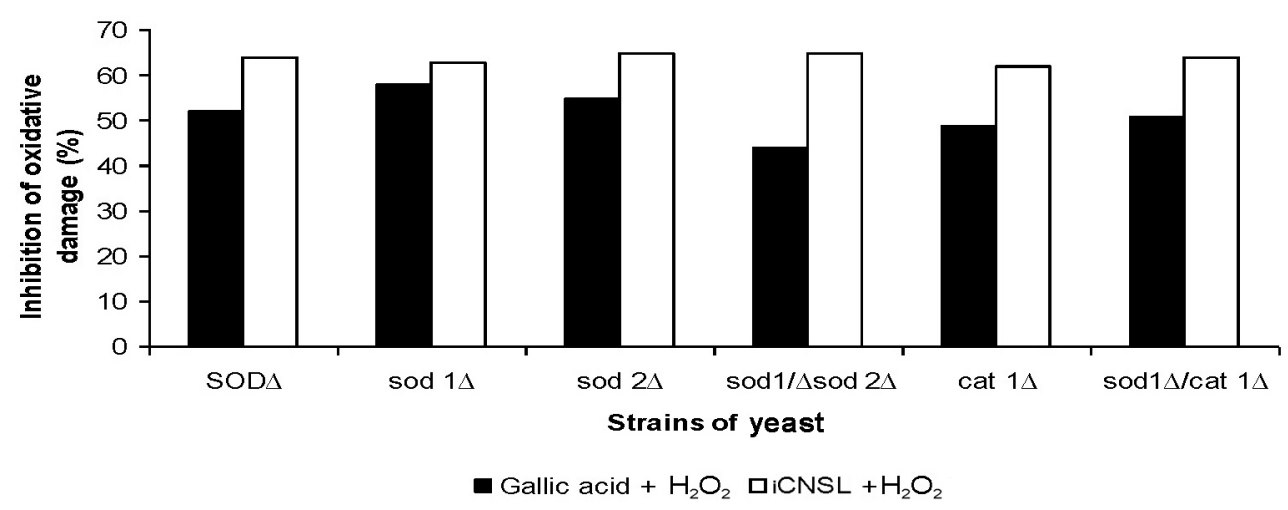

Figure 5. Percent of inhibition of immature cashew nut-shell liquid (iCNSL) against oxidative damage induced by $\mathrm{H}_{2} \mathrm{O}_{2}$ in different strains of Saccharomyces cerevisiae.

The possible antioxidant effect of iCNSL may be explained by the presence of phenolic compounds (Figure 2). It has been shown to possess an important antioxidant activity towards these radicals, which is principally based on the redox properties of their phenolic hydroxyl groups and the structural relationships between different parts of their chemical structure (Visioli et al., 1998). Cashew nut-shell liquid and hexane extracts of the other cashew products tested displayed significant antioxidant capacity, causing $100 \%$ inhibition of xanthine oxidase, and their antioxidant capacity to scavenge hydroxyl radicals was correlated with the concentration of alkyl phenols (Trevisan et al., 2006). Antioxidant activity of iCNSL was demonstrated against radical scavengers that trap peroxy radicals $\left(\mathrm{RO}_{2}\right)$. This activity happens because of their higher reactivity with these radicals (Rodrigues et al., 2006). Two mechanisms are commonly proposed to explain the antioxidant role of phenolic compounds: metal chelation and/or free radical scavenging, which can decrease the oxygen toxicity to cells (Khokhar and Owusu Apenten, 2003).

\section{Estimation of acetylcholinesterase activity}

iCNSL decreases AChE activity, as described in the literature (Ellman et al., 1961; Fenech, 1993; Rhee et al., 2001). The AChE activity of A. occidentale and its semi-synthetic derivatives was studied in erythrocytes. Isolated compounds tested decreased the enzymatic activity of AChE. The effect of phenolic lipids isolated from rye grains and CNSL from A. occidentale and their semi-synthetic derivatives on erythrocyte ghost's AChE activity was studied. It has been shown that all compounds tested decreased the enzymatic activity of AChE. This effect depends on the type of compounds studied. Three of them completely inhibit AChE activity at micromolar concentration. Four compounds isolated from A. occidentale (cardol, methyl cardol, alkyl phenol, and anacardic acid) and five semi-synthetic derivatives of hydrogenated alkyl phenol were tested for their AChE inhibitory activity. Phenolic lipids are natural amphiphilic long-chain homologues of phenol, resorcinol and catechol, which occur in numerous plants and microorganisms. They are non-isoprenoid compounds that consist of a phenolic structure with a long aliphatic 
hydrocarbon chain (of varying length and saturation) attached to it. They exhibit a high affinity with lipid bilayers and biological membranes and are able to modify the activity of membrane enzymes. Differences in the chemical structure of phenolic lipids are reflected in the different properties of these compounds. It has been reported that non-isoprenoid phenolic lipids of CNSL can be used as the start material for generating new candidates of AChE enzyme inhibitors (de Paula et al., 2007). Anacardic acid acts as a potent inhibitor of histone acetyltransferase and scientists are attempting to find other AChE inhibitors of plant origin, which might be of potential pharmacological interest. Three representative homologues of resorcinolic lipids and cardol completely inhibit AChE activity (Stasiuk et al., 2008).

These results support a role for iCNSL in providing strong cellular antioxidant protection against the potential deleterious effects of the free radicals produced by hydrogen peroxide and inhibition of AChE activity. It is also thought that it could be pathologically important in various neurodegenerative processes, including cognitive deficits that occur during normal cerebral aging, Alzheimer's and Parkinson's disease. These properties can be related to the chemical constituents of iCNSL, as well as anacardic acid, cardol and cardanol. As suggested by other authors, this study also indicates that iCNSL, which contains high contents of anacardic acids and is a natural antioxidant, in the dosages tested, could be better utilized in functional food formulations and may represent a cheap source of cancer chemopreventive agents.

\section{ACKOWLEDGMENTS}

We thank CENAUREMN, UFC and CNPq/PIBIC for financial support. The authors also acknowledge Jonathan Spottiswoode for grammatical correction.

\section{REFERENCES}

Abdelwahed A, Bouhlel I, Skandrani I, Valenti K, et al. (2007). Study of antimutagenic and antioxidant activities of gallic acid and 1,2,3,4,6-pentagalloylglucose from Pistacia lentiscus. Confirmation by microarray expression profiling. Chem. Biol. Interact. 165: 1-13.

Azam-Ali SH and Judge EC (2001). Small-Scale Cashew Nut Processing. FAO, Rugby.

da Silva KDP, Collares FP and Finzer JRD (2000). A simple and rapid method for estimating the content of solids in industrialized cashew juice. Food Chem. 70: 247-250.

De Lima SG (2005). Síntese e identificação de biomarcadores em óleos da Bacia de Campos e Bacia Potiguar: Identificação de 3-alquil-esteranos. Doctoral thesis, Instituto de Química, Unicamp, Campinas.

De Lima SG, Macedo AOA, Citó AMGL, Moita Neto JM, et al. (1997). Resina tipo resol do líquido da casca da castanha de caju. Anais Assoc. Bras. Quim. 46: 220-223.

de Paula AAN, Martins JBL, Gargano R, dos Santos ML, et al. (2007). Electronic structure calculations toward new potentially AChE inhibitors. Chem. Phys. Lett. 446: 304-308.

dos Santos ML and de Magalhães GC (1999). Utilization of cashew nut shell liquid from Anacardium occidentale as starting material for organic synthesis: A novel route to lasiodiplodin from cardols. J. Braz. Chem. Soc. 10: 13-20.

Ellman GL, Courtney KD, Andres V Jr and Feather-Stone RM (1961). A new and rapid colorimetric determination of acetylcholinesterase activity. Biochem. Pharmacol. 7: 88-95.

Fenech M (1993). The cytokinesis-block micronucleus technique: a detailed description of the method and its application to genotoxicity studies in human populations. Mutat. Res. 285: 35-44.

Gralla EB and Valentine JS (1991). Null mutants of Saccharomyces cerevisiae Cu,Zn superoxide dismutase: characterization and spontaneous mutation rates. J. Bacteriol. 173: 5918-5920.

Halliwell B and Gutteridge JMC (1999). Free Radicals in Biology and Medicine. Oxford University Press, Oxford. 
Ikeda R, Tanaka H, Uyama H and Kobayashi S (2002). Synthesis and curing behaviors of a crosslinkable polymer from cashew nut shell liquid. Polymer 43: 3475-3481.

Kamath V and Rajini PS (2007). The efficacy of cashew nut (Anacardium occidentale L.) skin extract as a free radical scavenger. Food Chem. 103: 428-433.

Khokhar S and Owusu Apenten RK (2003). Iron binding characteristics of phenolic compounds: some tentative structureactivity relations. Food Chem. 81: 133-140.

Kozubek A, Zarnowski R, Stasiuk M and Gubernator J (2001). Natural amphiphilic phenols as biofungicides. Cell Mol. Biol. Lett. 6: 351-355.

Kubo I, Komatsu S and Ochi M (1986). Molluscicides from the cashew Anacardium occidentale and their large-scale isolation. J. Agric. Food Chem. 34: 970-973.

Kubo I, Ochi M and Vieira PC (1993a). Antitumor agents from the cashew (Anacardium occidentale) apple juice. J. Agric. Food Chem. 41: 1012-1015.

Kubo I, Muroi H and Himejima M (1993b). Structure-antibacterial activity relations of anacardic acids. J. Agric. Food Chem. 41: 1016-1019.

Kumar PP, Paramashivappa PJ, Vithayathil PJ, Subra Rao PV, et al. (2002). Process for isolation of cardanol from technical cashew (Anacardium occidentale) nut shell liquid. J. Agric. Food Chem. 50: 4705-4708.

Liu XF, Elashvili I, Gralla EB, Valentine JS, et al. (1992). Yeast lacking superoxide dismutase. Isolation of genetic suppressors. J. Biol. Chem. 267: 18298-18302.

Lizhi Z (2003). Investigating the biosynthesis of polyacetylenes: Synthesis of deuterated linoleic acids and mechanism studies of DMDS addition to 1,4-enynes. Ph.D. thesis, Miami University, The Graduate School, Oxford.

Logrado LPL, Silveira D, Romeiro LAS, de Moraes MO, et al. (2005). Synthesis and biological evaluation of new salicylate macrolactones from anacardic acids. J. Braz. Chem. Soc. 16: 1217-1225.

Marres CA, Van Loon AP, Oudshoorn P, Van Steeg H, et al. (1985). Nucleotide sequence analysis of the nuclear gene coding for manganese superoxide dismutase of yeast mitochondria, a gene previously assumed to code for the Rieske iron-sulphur protein. Eur. J. Biochem. 147: 153-161.

Massoulie J, Pezzementi L, Bon S, Krejci E, et al. (1993). Molecular and cellular biology of cholinesterases. Prog. Neurobiol. 41: 31-91.

Melo-Cavalcante AA, Rubensam G, Picada JN, Gomes da SE, et al. (2003). Mutagenicity, antioxidant potential, and antimutagenic activity against hydrogen peroxide of cashew (Anacardium occidentale) apple juice and cajuina. Environ. Mol. Mutagen. 41: 360-369.

Melo-Cavalcante AAC, Rübensam G, Erdtmann B, Brendel M, et al. (2005). Cashew (Anacardium occidentale) apple juice lowers mutagenicity of aflatoxin B1 in S. thyphimurium. Genet. Mol. Biol. 28: 328-333.

Murthy BG, Samban MA and Aggarwal JS (1968). Identification of some naturally occurring alkyl-substituted phenols in cashew-nut shell liquid by chromatographic techniques. J. Chromatogr. 32: 519-528.

Resck IS, dos Santos ML and Romeiro LAS (2005). New application of triphosgene in a convenient synthesis of 3-aryl-1,3benzoxazine-2,4-diones from anacardic acids. Heterocycles 65: 311-318.

Rhee IK, van de Meent M, Ingkaninan K and Verpoorte R (2001). Screening for acetylcholinesterase inhibitors from Amaryllidaceae using silica gel thin-layer chromatography in combination with bioactivity staining. J. Chromatogr. A 915: 217-223.

Rodrigues FHA, Feitosa JPA, Ricardo NMPS, Franca FCF, et al. (2006). Antioxidant activity of cashew shell nut liquid (CNSL) derivatives on the thermal oxidation of synthetic cis-1,4-polyisoprene. J. Braz. Chem. Soc. 17: 265-271.

Rosa RM, Melecchi MI, Halmenschlager RC, Abad FC, et al. (2006). Antioxidant and antimutagenic properties of Hibiscus tiliaceus L. methanolic extract. J. Agric. Food Chem. 54: 7324-7330.

Shobha SV and Ravindranath B (1991). Supercritical carbon dioxide and solvent extraction of the phenolic lipids of cashew nut (Anacardium occidentale) shells. J. Agric. Food Chem. 39: 2214-2217.

Silva MSS, Citó AMGL, Chaves MH and Lopes JAD (2005). Triterpenóides tipo cicloartano de própolis de Teresina - Pi. Quim. Nova 28: 801-804.

Skerget M, Kotnik P, Hadolin M, Hras HR, et al. (2005). Phenols, proanthocyanidins, flavones and flavonols in some plant materials and their antioxidant activities. Food Chem. 89: 191-198.

Smith MA, Rottkamp CA, Nunomura A, Raina AK, et al. (2000). Oxidative stress in Alzheimer's disease. Biochim. Biophys. Acta 1502: 139-144.

Stasiuk M, Bartosiewicz D and Kozubek A (2008). Inhibitory effect of some natural and semisynthetic phenolic lipids upon acetylcholinesterase activity. Food Chem. 108: 996-1001.

Steinman HM (1980). The amino acid sequence of copper-zinc superoxide dismutase from bakers' yeast. J. Biol. Chem. 255: 6758-6765. 
Toschi TG, Caboni MF, Penazzi G, Lercker G, et al. (1993). A study on cashew nut oil composition. J. Am. Oil Chem. Soc. 70: 1017-1020.

Trevisan MTS, Pfundstein B, Haubner R, Wurtele G, et al. (2006). Characterization of alkyl phenols in cashew (Anacardium occidentale) products and assay of their antioxidant capacity. Food Chem. Toxicol. 44: 188-197.

Visioli F, Bellosta S and Galli C (1998). Oleuropein, the bitter principle of olives, enhances nitric oxide production by mouse macrophages. Life Sci. 62: 541-546.

Wang C (1998). The role of lipids in disease resistance and fruit ripening tomato. Ph.D. thesis, Rutgers University, New Brunswick. 